\title{
Effects of $2100 \mathrm{MHz}$ radio frequency radiation on ductus epididymis tissue in rats
}

\author{
Erdemli $\mathrm{C}^{1}$, Omeroglu $\mathrm{S}^{1}$, Sirav $\mathrm{B}^{2,3}$, Colbay $\mathrm{M}^{4}$, Seyhan $\mathrm{N}^{2,3}$, Ozkan $\mathrm{S}^{5}$, Yetkin $\mathrm{I}^{4}$ \\ Gazi University, Faculty of Medicine, Department of Biophysics, Ankara, Turkey. \\ bahriyes76@gmail.com
}

\begin{abstract}
PURPOSE: The use of mobile phones is widespread since the beginning of 1990s. A great debate exists about the possible damage that the Radio Frequency - RF radiation from mobile phones exerts on different organs. The objective of this study was to investigate the possible histopathological effects of $2100 \mathrm{MHz} R \mathrm{~F}$ radiation on rat ductus epididymis tissue using a light microscopy and immunohistochemical method after one or two month exposure.

MATERIALS AND METHODS: The study was performed on 36 adult Wistar albino rats. $2100 \mathrm{MHz}$ RF radiation was used with a specific absorption rate (SAR) of $0.36 \mathrm{~W} / \mathrm{kg}$ for $30 \mathrm{~min} / \mathrm{day}, 6$ days per week for one or two months. There were 3 groups ( $n=6$ for each group): one month RF exposed group, two months RF exposed group, and the control group.

RESULTS: At the end of the study, the structural changes in ductus epididymis tissue were evaluated. In both $2100 \mathrm{MHz}$ RF exposed groups, the rat ductus epididymis sperm were not observed in some channels, a reduction in sperm density in some of the channels drew an attention. The loss of connective tissue and edematous areas were observed in cross channel interstitial connective tissue. In addition, it was observed that vascularization was highly increased with respect to the control group in cross-channel interstitial connective tissue. CONCLUSION: $2100 \mathrm{MHz}$ RF exposure resulted in some structural changes in the male genital ducts of rats (Tab. 1, Fig. 5, Ref 20). Text in PDF www.elis.sk.

KEY WORDS: radio frequency radiation, ductus epididymis, immunohistochemistry, light microscope, rats.
\end{abstract}

\section{Introduction}

Recently, a series of experiments were performed to investigate possible effects of exposure to Radio Frequency - RF Radiation. A number of studies reported several unpleasant effects of mobile phone usage on different body organs, including reproductive organs $(1-4)$. Mobile phones have now become very important device for millions of individuals. Most users take their mobile phones in their pocket or bags very close to their genitals. Therefore, there is a growing interest to investigate the effects of RF radiation due to mobile phone usage on reproduction. One of the previous studies conducted by Dasdag et al (3) investigated whether there are adverse effects due to RF exposure in male Wistar albino rats. Dasdag et al (3) assessed the testes of rats after the exposure of $900 \mathrm{MHz}, 0.141 \mathrm{~W} / \mathrm{kg}$ for $2 \mathrm{~h} /$ day for 1 month. They did not observe any abnormalities regarding the

${ }^{1}$ Gazi University, Faculty of Medicine, Department of Histology \& Embryology, Ankara, Turkey, ${ }^{2}$ Gazi University, Faculty of Medicine, Department of Biophysics, Ankara, Turkey, ${ }^{3}$ Gazi Non-Ionizing Radiation Protection Center- GNRP, Ankara, Turkey, ${ }^{4}$ Gazi University, Faculty of Medicine, Department of Internal Medicine, Endocrinology, Ankara, Turkey, and ${ }^{5}$ Gazi University, Faculty of Medicine, Department of Public Health, Ankara, Turkey

Address for correspondence: B. Sirav, Dr, Department of Biophysics, Faculty of Medicine, Gazi University, 06510 Ankara, Turkey.

Phone: +90.3122026941 , Fax: +90.3122129023 sperm number and morphology. They also performed two similar studies, except for exposure duration. The first one assessed the testes of rats exposed to $900 \mathrm{MHz}$ in a waveguide, with an exposure condition SAR $0.52 \mathrm{~W} / \mathrm{kg}$ for $20 \mathrm{~min} /$ day for 1 month (4). The second study's exposure was performed for 10 months. No differences were observed in the percentages of epididymal normal and abnormal sperms, the epididymal sperm count, motility and reproductive organ weights between control and experimental groups in these studies. The potential adverse effects of mobile phone exposure on male fertility were extensively investigated in the past decade by many researchers, who reported significant adverse effects of RF on testis and seminal parameters, including motility, concentration and morphology (5-6). However, more supporting evidence and research is definitely needed in this topic. The aim of this study was to evaluate the possible effects of $2100 \mathrm{MHz}$ RF exposure in two different exposure durations on the ductus epididymis tissue of rats, which is an important region for sperm maturation. $2100 \mathrm{MHz}$ was used due to the increasing demands of 3-G technologies.

\section{Materials and methods}

\section{Experimental animals and treatments}

Eighteen adult male Wistar albino rats with body weights between 220-270 g were used in the experiment. The rats were randomly separated into 3 groups equally: one month RF exposed 


\section{9-764}

group; denoted by RF-1 $(n=6)$, two months RF exposed group denoted by RF-2 $(n=6)$, and the control group denoted by $\mathrm{C}(\mathrm{n}$ $=6$ ). All rats were housed in plexiglass cages in a room with controlled temperature $\left(22^{\circ} \mathrm{C}\right)$, humidity $(50-55 \%)$ and a 12-hours light-dark. All activities within the scope of the study were performed with the approval of Gazi University Experimental Animal Ethics Committee under the supervision of a veterinarian and in compliance with the provisions of the Strasbourg Universal Declaration of Animal Rights of 1986. The rats were fed laboratory pellet chow and water was given ad libitum. The experiment was performed after a stabilization period in the laboratory for several days. None of the animals died during the experiment. The RF groups were exposed to $2100 \mathrm{MHz}$ RF radiation for 30 min/day, 6 days per week for one month and two months. Rats of the control group were housed in their home cages during the entire experimental period without subjecting to any experimental manipulation. The rats were sacrificed by decapitation following anesthesia by intramuscular injection of ketamine $(50 \mathrm{mg} / \mathrm{kg})$ and xylazine $(5 \mathrm{mg} / \mathrm{kg})$.

\section{Exposure system}

The vector signal generator (Rohde \& Schwartz, SMBV100A, Germany) was used to create a RF radiation in the experimental setup (Fig. 1). Emitted power of the generator was fixed during the whole exposure durations. ETS Lindgren horn antenna (ETS Lindgren, Model 3164-03, USA) was used to emit the RF radiation from the generator. Polymethyl methacrylate plastic cage $(15 \times 20 \times 20 \mathrm{~cm})$, which the rats were housed in, was placed symmetrically along the axis, which is perpendicular and $5 \mathrm{~cm}$ below the mid-line of the horn antenna. The cage was constantly aerated to avoid the possibility of any increase in temperature inside the cage. A cage was placed in the near field of the antenna to obtain sufficient field intensity. Applied RF fields' electric field was measured with EMR 300 (Narda, Germany) via the electric field probe type 8.3. The root mean square value of electric field $\left(\mathrm{E}_{\mathrm{RMS}}\right)$ was found as $21.25 \mathrm{~V} / \mathrm{m}$. The $\mathrm{RF}$ environmental background level was $0.1-0.21 \mathrm{~V} / \mathrm{m}$. The average power density was measured at a reference point, which was the mid-point of the bottom of the cage wall facing the horn antenna. The maximum power density was observed along the axis of the antenna and it decreased uniformly with the distance from the antenna's axis.

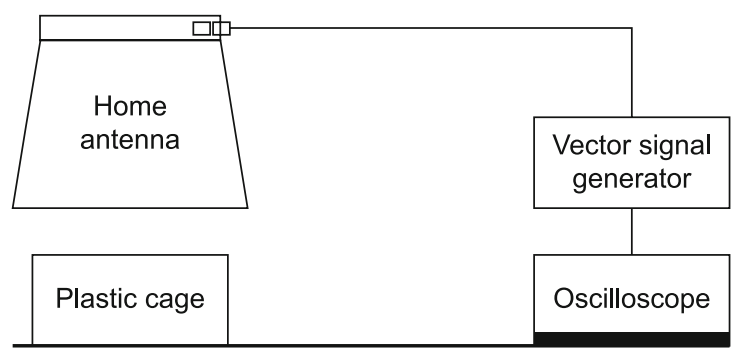

Fig. 1. RF exposure system.
SAR is a measure of the rate of radiation energy absorption per unit weight of tissue and is expressed in units of watts per kilogram (W/kg). It is a widely used dosimetric quantity to compare the absorbed energy in different biological tissues. The SAR value was estimated by measurements and calculations in this experiment.

SAR was calculated using the following equation:

$\mathrm{SAR}=\sigma / \rho\left[\mathrm{E}_{\mathrm{RMS}}{ }^{2}\right][\mathrm{W} / \mathrm{kg}]$

where; $\mathrm{E}_{\mathrm{RMS}}$ is the root mean square value of the electric field $(\mathrm{V} / \mathrm{m}), \mathrm{s}$ is the mean electrical conductivity of the tissues in Siemens $/$ meter $(\mathrm{S} / \mathrm{m})$ and $\mathrm{r}$ is the mass density $\left(\mathrm{kg} / \mathrm{m}^{3}\right)(7-8)$. The rat body was assumed an equivalent tissue based on the average of the dielectric properties of the 36 tissues in the rat segmented at Brook Air Force Base. Conductivity (0.87 S/m) and mass density (1105 $\mathrm{kg} / \mathrm{m}^{3}$ ) were derived for the equivalent tissue by using dielectric properties and mass densities of these tissues. The RF exposure in the experiment resulted in a whole body average SAR of 0.36 $\mathrm{W} / \mathrm{kg}$ with an $\mathrm{E}_{\mathrm{RMS}}$ field of $21.25 \mathrm{~V} / \mathrm{m}$.

Body temperature of rats was recorded by rectal measurements prior and after an exposure session. The RF exposure did not result in any rectal temperature increase.

\section{Histological assessment}

After sacrifice, the epididymis tissues of each rat were immediately removed and put in the $10 \%$ neutral phosphate-buffer formaldehyde solution for 72 hours at room temperature. After fixation, the specimens were dehydrated in a graded alcohol series, embedded in paraffin wax, and cut into $5 \mu \mathrm{m}$ sections, deparaffinised in xylene and stained in Hematoxylin-Eosin (Merck, Darmstadt, Germany) and Masson trichrome. The structural changes in ductus epididymis were evaluated.

\section{Immunohistochemistry}

Ductus epididymis tissues from each group were fixed in neutral formalin for $72 \mathrm{~h}$ and processed for paraffin embedding. Sections of 4-5 $\mu \mathrm{m}$ thickness were processed for polylysine-covered microscope slides. For immunohistochemical examination, slides were stored in a microwave oven in $1 \mathrm{M}$ citrate buffer for caspase-3 and in 1 M EDTA buffer (LabVision, USA). Endogenous peroxidase activity was blocked with $3 \%$ hydrogen peroxide (LabVision). Epitopes were stabilized by application of Ultra V Block (Lab Vision, USA) and slides were then incubated with caspase- 3 (rabbit polyclonal antibody Ab-4, $1 \mathrm{mg} / \mathrm{mL}$, NewMarker, USA) and VEGF (rabbit polyclonal antibody Ab-1, $1 \mathrm{mg} / \mathrm{mL}$, NewMarker, USA) for $60 \mathrm{~min}$ at room temperature. Next, the biotinylated secondary antibody (Ultravision Detection System Anti-Rabbit HRP (RTU) LabVision), and streptavidin peroxidase (LabVision) were applied to the slides. 3-Amino-9-ethylcarbazole (LabVision) was used as chromogen. Finally, the slides were counterstained with hematoxylin and examined with a light microscope.

\section{Statistical analysis}

In this study, the weights of ductus epididymis tissue of all groups were evaluated with the Mann-Whitney U test. Data were presented as the mean \pm standard deviation (SD). $\mathrm{P}$ value at 0.05 was considered as the level of significance. 

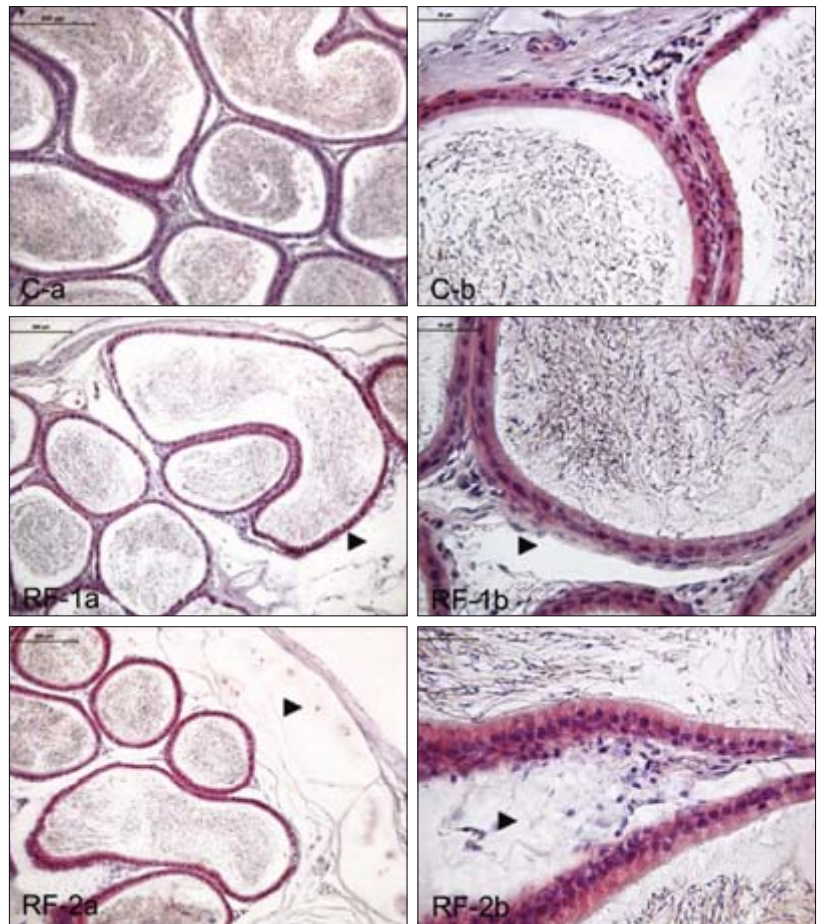

Fig. 2. Tissue morphometries were shown with Hematoxylin-Eosin (H.E.). Abbreviations; C-a: Control group (H.E X10), C-b: Control group: (H.E X40), RF-1a: one month RF exposed group (H.E X10), RF-1b: one month RF exposed group (H.E X40), RF-2a: two months RF exposed group (H.E X10), and RF-2b: two months RF exposed group (H.E X40).
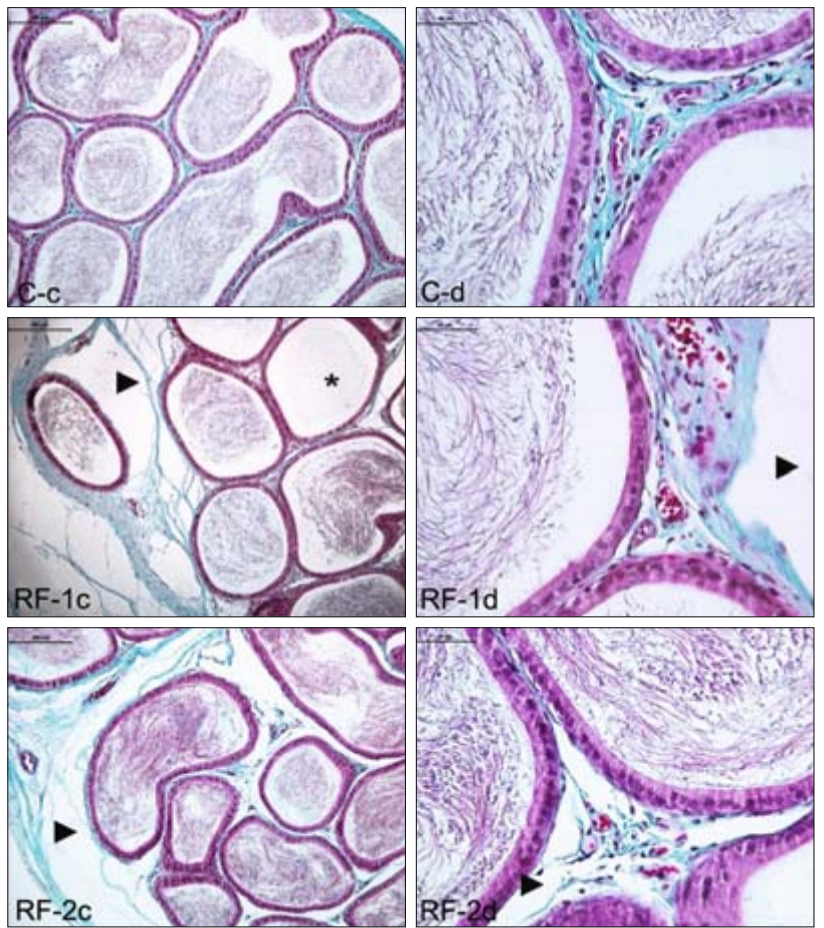

Fig. 3. Tissue morphometries were shown with Masson Trichrome (M.T). Abbreviations; C-c: Control group: (M.T X10), C-d: Control group: (M.T X40), RF-1c: one month RF exposed group (M.T X10), RF-1d: one month RF exposed group (M.T X40), RF-2c: two months RF exposed group (M.T X40), RF-2d: two months RF exposed group (M.T X40).
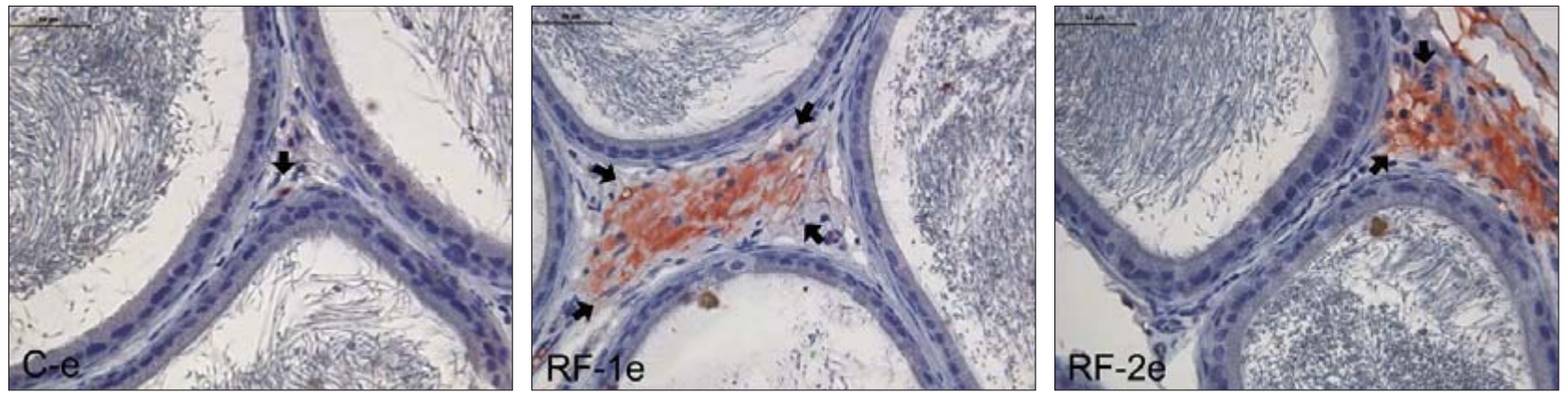

Fig. 4. Immunohistochemical Caspase-3 diagrams (immunoperoxidase - hematoxylin X 40). C-e: Control group, RF-1e: one month RF exposed group, RF-2e: Two months RF exposed group.
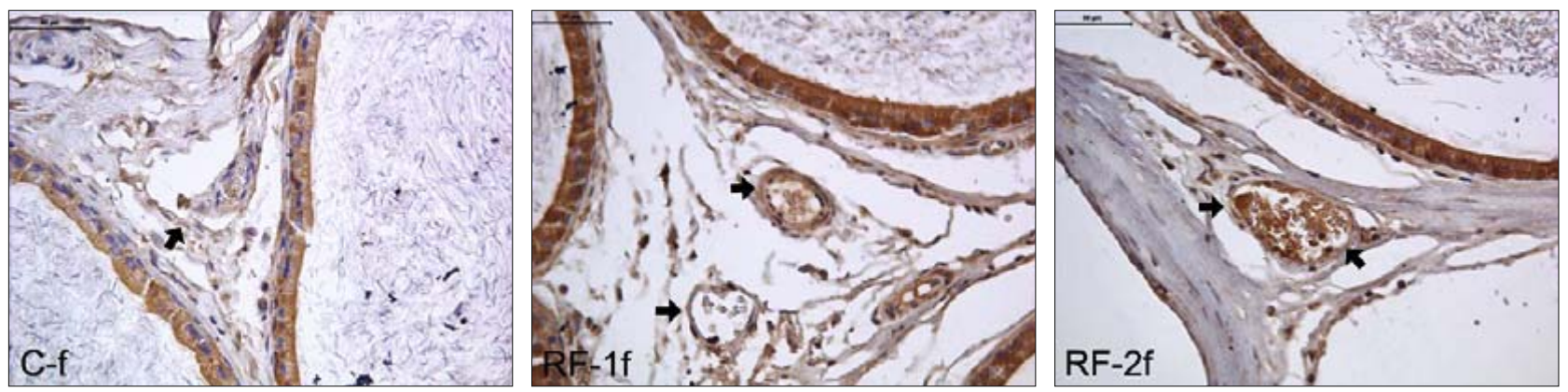

Fig. 5. Immunohistochemical VEGF diagrams (immunoperoxidase - hematoxylin X 40). C-f: Control group, RF-1 f : one month RF exposed group, RF-2 f: Two months RF exposed group. 


\section{Results}

\section{Tissue morphometry}

In the assessments of 1 month RF exposed group, sperm was not observed in some channels, a reduction in sperm density in some of the channels of ductus epididymis drew attention, too. Loss and damage of connective tissue was observed in cross- channel interstitial connective tissue, where edematous areas take in. In addition, it was observed that vascularization was markedly increased relative to the control group in cross-channel interstitial connective tissue.

In 2 months RF exposed group, sperm density was decreased in some channels of their ductus epididymis with respect to the control group. Decreases in height from place to place order distortion of epithelial cells, sperm was observed. In interstitial connective tissue between channels, the presence of edematous areas, with respect to 2-month control group, was significantly increased, blood supply had been seen significantly (Figs 2 and 3).

\section{Immunohistochemical results}

Analysis of rat ductus epididymis tissues with the Caspase-3 immunohistochemical staining ' both RF exposed group's interstitial connective tissue showed an increased immunoreactivity, when compared to the control group (Fig. 4).

In both RF exposed groups, an increased immunoreactivity was observed in vessels of peritubular connective tissue via VEGF immunohistochemical staining (Fig. 5).

\section{Statistical analysis}

In our study, we compared the ductus epididymis in the experimental groups and there was no statistically significant change in terms of weight $(\mathrm{p}=0.631, \mathrm{p}=0.078)$.

\section{Discussion}

The relationship between radiofrequency electromagnetic fields emitted from mobile phone and infertility is a matter of continuing debate. Some studies did not find any significant effect of RF radiation on testicular histology, sperm count and morphology $(5,9-10)$, others indicated that cell phone might have a wide spectrum of detrimental effects on sperm parameters (11-14). There were many studies suggesting that there will be some relation between mobile phone radiation and the quality of sperms. Agarwal et al (15) made experiments in neat semen samples from normal healthy donors $(n=23)$ and infertile patients $(n=9)$ exposed to RF radiation. They showed a significant decrease in sperm motility and viability, increase in ROS level, and decrease in ROSTAC score. Levels of TAC and DNA damage showed no significant

Tab. 1. Control and RF exposed groups' ductus epididymis weights.

\begin{tabular}{lcc}
\hline & \multicolumn{2}{c}{ Ductus Epididymis weight $(\mathrm{g})$} \\
\cline { 2 - 3 } & Mean \pm SD & Median $(\min -\max )$ \\
\hline $\mathrm{C}$ & $0.208 \pm 0.0095$ & $0.210(0.191-0.219)$ \\
$\mathrm{RF}-1$ & $0.212 \pm 0.0163$ & $0.215(0.191-0.231)$ \\
$\mathrm{RF}-2$ & $0.283 \pm 0.0340$ & $0.2770(0.244-0.341)$ \\
\hline
\end{tabular}

differences from the unexposed group. Kesari \& Behari (11) used 70 days old Wistar rats with mobile phone RF exposure for $2 \mathrm{~h}$ per day for 45 days. A significant decrease in the level of testosterone and an increase in caspase- 3 activity were found in the RF-exposed animals. Distortions in sperm head and mid piece of sperm mitochondrial sheath were also observed as captured by Transmission Electron Microscope (TEM). They also showed progeny from RFexposed rats with significant decreases in number and weight with respect to sham-exposed animals. They concluded that a reduction in testosterone, an increase in caspase-3, and distortion in spermatozoa could be caused by overproduction of reactive oxygen species (ROS) in animals under mobile phone radiation exposure. However Lee et al (9) examined the effects of combined exposure to RF radiation on rat testicular function, specifically with respect to sensitive processes such as spermatogenesis. Male rats were exposed to single code division multiple access (CDMA) and wideband code division multiple access (WCDMA) RF signals for 12 weeks. The RF exposure schedule comprised $45 \mathrm{~min} /$ day, 5 days/week for a total of 12 weeks. The whole-body average specific absorption rate (SAR) of CDMA and WCDMA was $2.0 \mathrm{~W} /$ $\mathrm{kg}$ each or $4.0 \mathrm{~W} / \mathrm{kg}$ in total. They then investigated the correlates of testicular function, such as: sperm count in the cauda epididymis, testosterone concentration in the blood serum, malondialdehyde concentrations in the testes and epididymis, frequency of spermatogenesis stages, and appearance of apoptotic cells in the testes. They also immunoblotted for p53, bcl2, GADD45, cyclin $\mathrm{G}$, and HSP70 in the testes of sham- and combined RF-exposed animals. Based on the results, they concluded that simultaneous exposure to CDMA and WCDMA RF radiation at $4.0 \mathrm{~W} / \mathrm{kg} \mathrm{SAR}$ did not have any observable adverse effects on rat spermatogenesis. In their previous study, Lee et al (16) again examined the histological changes by radiofrequency (RF) fields on rat testis, specifically with respect to sensitive processes such as spermatogenesis. In that case, male rats were exposed to $848.5 \mathrm{MHz} \mathrm{RF}$ for 12 weeks. RF exposure schedule consisted of two 45-min RF exposure periods, separated by a 15-min interval and the whole-body average specific absorption rate (SAR) of RF was $2.0 \mathrm{~W} / \mathrm{kg}$. They investigated correlates of testicular function, such as: sperm counts in the cauda epididymis, malondialdehyde concentrations in the testes and epididymis, frequency of spermatogenesis stages, germ cell counts, and appearance of apoptotic cells in the testes and also performed p53, bcl-2, caspase 3, p21, and PARP immunoblotting of the testes in sham- and RF-exposed animals. Based on these results, they concluded that sub chronic exposure to $848.5 \mathrm{MHz}$ with $2.0 \mathrm{~W} / \mathrm{kg}$ SAR RF did not have any observable adverse effects on rat spermatogenesis. Lukac et al (17) evaluated the effects of $1800 \mathrm{MHz}$ GSM-like radiofrequency electromagnetic waves (RF-EMW) exposure on bovine semen. The experimental samples were analyzed in vitro in four time periods $(0,30,120$ and 420 min) and compared to unexposed samples (control). Spermatozoa motility was determined by computer assisted semen analyzer (CASA). Evaluation of the percentage of motile spermatozoa showed a significant decrease in experimental groups after 120 and $420 \mathrm{~min}$ of culture, when exposed to microwaves, in comparison to the control. Similar spermatozoa motility inhibition was 
detected for the percentage of progressively motile spermatozoa, too. The average path distance decreased significantly in the experimental groups after 30 and 420 min of culture. Path velocity increased in the experimental groups exposed to RF after 30 minutes of culture, but subsequently decreased after $420 \mathrm{~min}$ of culture, in comparison to the control. This indicates a possible initial stimulation and subsequent velocity inhibition of bovine spermatozoa under RF exposure. Changes in spermatozoa motility were also detected for some fine parameters, too. A significant decrease was noted for the amplitude of lateral head displacement in the experimental group after 420 minutes of culture. Detailed in vitro motility analysis of bovine spermatozoa exposed to microwave radiation suggested that the parameters of path and velocity at the beginning of the culture significantly increased, but after longer cultivation (420 minutes) a significant decrease occurred in the experimental group as compared to the control. In general, the results of this experiment indicated a negative time-dependent effect of $1800 \mathrm{MHz}$ RF radiation on bovine spermatozoa motility. La Vignera et al (18) performed their study in rats, mice, and rabbits using a similar design based on mobile phone RF exposure for variable lengths of time. They showed that RF exposure decreased sperm count and motility and increased oxidative stress. In humans, 2 different experimental approaches have been followed in their study: one has explored the effects of RF radiation directly on spermatozoa and the other has evaluated the sperm parameters in men using or not using mobile phones. The results showed that human spermatozoa exposed to RF exposure had decreased motility, morphometric abnormalities, and increased oxidative stress, whereas men using mobile phones have decreased sperm concentration, decreased motility (particularly rapid progressive motility), normal morphology, and decreased viability. They concluded that those abnormalities seemed to be directly related to the duration of mobile phone use. Falzone et al (2) evaluated the effect of RF radiation on sperm-specific characteristics to assess the fertilizing competence of sperm. Highly motile human spermatozoa were exposed for $1 \mathrm{~h}$ to $900 \mathrm{MHz}$ RF radiation at a specific absorption rate of $2.0 \mathrm{~W} / \mathrm{kg}$ and examined at various times after exposure. The acrosome reaction was evaluated using a flow cytometry. The radiation did not affect sperm propensity for the acrosome reaction. Morphometric parameters were assessed using a computer-assisted sperm analysis. A significant reduction in sperm head area $\left(9.2 \pm 0.7 \mu \mathrm{m}^{2}\right.$ vs $\left.18.8 \pm 1.4 \mu \mathrm{m}^{2}\right)$ and acrosome percentage of the head area $(21.5 \pm 4 \%$ v. $35.5 \pm 11.4 \%)$ was reported among exposed sperm compared to unexposed controls. Sperm-zona binding was assessed directly after the exposure using the hemizona assay. The mean number of zonabound sperm of the test hemizona and controls was $22.8 \pm 12.4$ and $31.8 \pm 12.8$, respectively. They concluded that although $\mathrm{RF}$ radiation exposure did not adversely affect the acrosome reaction, it had a significant effect on sperm morphometry. A significant decrease in sperm binding to the hemizona was observed. Erogul et al (1) found that RF emitted by cellular phones affected human sperm motility. A total number of 27 males were enrolled in their study. The semen sample obtained from each participant was divided equally into two parts. One of the specimens was exposed to EMR emitted by an activated $900 \mathrm{MHz}$ cellular phone, whereas the other was not. Statistically significant changes were observed in the rapid progressive, slow progressive and no-motility categories of sperm movement. RF exposure caused a subtle decrease in the rapid progressive and slow progressive sperm movement. It also caused an increase in the no-motility category of sperm movement. There was no statistically significant difference in the sperm concentration between the two groups in that study. Dasdag et al (3) assessed the testes of rats irradiated with $900 \mathrm{MHz}$ with and exposure condition SAR $0.141 \mathrm{~W} / \mathrm{kg}$ for $2 \mathrm{~h} /$ day for 1 month. They did not observe abnormalities regarding the sperm number and morphology. They have confirmed their study later $(4,19)$. Rajaei et al (20) investigated the ductus epididymis and ductus deference tissues of rats after the exposure of $50 \mathrm{~Hz}$ magnetic fields with 4 hour/day, 6 days/ week, for two months. The exposed group's lumen radius and the height of epithelial tissue were found statistically decreased with respect to sham or control animals. The effect of electromagnetic field exposure on biological systems is viewed as a non- specific stress and its impact on biochemistry and physiology remains unknown. So, further researches are needed.

\section{References}

1. Erogul O, Oztas E, Yildirim I, Kir T, Aydur E, Komesli G, Irkilata HC, Irmak MK, Peker AF. Effects of electromagnetic radiation from a cellular phone on human sperm motility: an in vitro study. Arch Med Res 2006; 37 (7): 840-843.

2. Falzone N, Huyser C, Becker P, Leszczynski D, Franken DR. The effect of pulsed 900-MHz GSM mobile phone radiation on the acrosome reaction, head morphometry and zona binding of human spermatozoa. Int J Androl 2011; 34 (1): 20-26.

3. Dasdag S, Ketani MA, Akdag Z, Ersay AR, Sari I, Demirtas OC, Celik MS. Whole-body microwave exposure emitted by cellular phones and testicular function of rats. Urol Res 1999; 27 (3): 219-223.

4. Dasdag S, Akdag MZ, Aksen F, Yilmaz F, Bashan M, Dasdag M, Celik MS. Whole body exposure of rats to microwaves emitted from a cell phone does not affect the testes. Bioelectromagnetics 2003; 24 (3): 182-188.

5. Agarwal A, Deepinder F, Sharma RK, Ranga G, Li J. Effect of cell phone usage on semen analysis in men attending infertility clinic: an observational study. Fertil Steril 2008; 89: 124-128.

6. Fejes I, Koloszár S, Szöllosi J, Závaczki Z, Pál A. Is semen quality affected by male body fat distribution? Andrologia 2005; 37 (5): 155-159.

7. International Commission on Non-Ionizing Radiation Protection, ICNIRP. Guidelines for limiting exposure to time varying electric, magnetic and electromagnetic fields (up to $300 \mathrm{GHz}$ ). Health Physics 1998; 74: 494-522.

8. Institute of Electrical and Electronics Engineers/American National Standards Institute (IEEE/ANSI). IEEE C95.1-1991: IEEE standard for safety levels with respect to human exposure to radio frequency electromagnetic fields, $3 \mathrm{kHz}$ to $300 \mathrm{GHz}$. New York: IEEE Inc.1992; 1-76.

9. Lee HJ, Jin YB, Kim TH, Pack JK, Kim N, Choi HD, Lee JS, Lee YS. The effects of simultaneous combined exposure to CDMA and WCDMA electromagnetic fields on rat testicular function. Bioelectromagnetics 2011. doi: 10.1002/bem.20715. 


\section{9-764}

10. Nisbet OH, Nisbet C, Akar A, Cevik M, Karayigit MO. Effects of exposure to electromagnetic field $(1.8 / 0.9 \mathrm{GHz})$ on testicular function and structure in growing rats. Res Vet Sci 2011; 93 (2): 1001-1005.

11. Kesari KK, Behari J. Microwave exposure affecting reproductive system in male rats. Appl Biochem Biotechnol 2010; 162 (2): 416-428.

12. Kesari KK, Kumar S, Behari J. Effects of radiofrequency electromagnetic wave exposure from cellular phones on the reproductive pattern in male Wistar rats. Appl Biochem Biotechnol 2011; 164 (4): 546-559.

13. Kesari KK, Behari J. Evidence for mobile phone radiation exposure effects on reproductive pattern of male rats: role of ROS. Electromagn Biol Med 2012; 31 (3): 213-222.

14. Kumar S, Kesari KK, Behari J. Influence of microwave exposure on fertility of male rats. Fertil Steril 2011; 15 (4): 1500-1502.

15. Agarwal A, Desai NR, Makker K, Varghese A, Mouradi R, Sabanegh E, Sharma R. Effects of radiofrequency electromagnetic waves (RF-EMW) from cellular phones on human ejaculated semen: an in vitro pilot study. Fertil Steril 2009; 92 (4): 1318-1325.
16. Lee HJ, Pack JK, Kim TH, Kim N, Choi SY, Lee JS, Kim SH, Lee YS. The lack of histological changes of CDMA cellular phone-based radio frequency on rat testis. Bioelectromagnetics 2010; 31 (7): 528-534.

17. Lukac N, Massanyi P, Roychoudhury S, Capcarova M, Tvrda E, Knazicka Z, Kolesarova A, Danko J. In vitro effects of radiofrequency electromagnetic waves on bovine spermatozoa motility. J Environ Sci Health A Tox Hazard Subst Environ Eng 2011; 46 (12): 1417-1423.

18. La Vignera S, Condorelli RA, Vicari E, D’Agata R, Calogero AE. Effects of the exposure to mobile phones on male reproduction: a review of the literature. J Androl 2012; 33 (3): 350-356.

19. Dasdag S, Akdag MZ, Ulukaya E, Uzunlar AK, Yegin D. Mobile phone exposure does not induce apoptosis on spermatogenesis in rats. Arch Med Res 2008; 39 (1): 40-44.

20. Rajaei F, Farokhi M, Ghasemi N, Pahlevan A. Effects of extremely low-frequency magnetic field on mouse epididymis and deferens ducts. Iran J Reprod Med 2009; 7 (2): 85-89. 